\title{
Implementation of Improved Jigs and Fixtures in the Production of Non-Active Rotary Paddy Weeder
}

\author{
Ankitesh Shrivastava $^{1^{\star}}$ and Ajay Verma ${ }^{2}$ \\ ${ }^{1}$ Production Engineering, Bhilai Institute of Technology, Durg, Chhattisgarh, India \\ ${ }^{2}$ Department of Farm Machinery and Power Engineering, IGKV Raipur, Chhattisgarh, India
}

\begin{abstract}
Paddy weeder is a manual weeding tool and is used to control weeds in the concerned area. Presently, the manufacturing of paddy weeder employs traditional methods, i.e. production process was being executed without the implementation of jigs. Jigs are special work holding and tool guiding device. The use of jigs and fixtures is an economical way to produce a component in mass, and hence they serve as an important component for mass production system. The primary objective of this research was to increase the production by reducing operation time thus reducing the cost associated with it. The jigs and fixtures were firstly designed with the software solidworks. The implementation of improved jigs proved remarkably efficient and helped in saving $35 \%$ of the time elapsed in the production cycle, with increased worker safety and hence, proved helpful in facilitating mass production.
\end{abstract}

Copyright@2014 STAR Journal. All Rights Reserved.

\begin{tabular}{l} 
Article Information \\
Article History: \\
Received : 12-09-2014 \\
Revised : 13-11-2014 \\
Accepted : 18-12-2014 \\
\hline Keywords: \\
Paddy weeder \\
Jigs \\
Solid works \\
Mass production \\
\hline *Corresponding Author: \\
Ankitesh Shrivastava \\
E-mail: \\
ankiteshrivastava@gmail.com
\end{tabular}

\section{INTRODUCTION}

A weed can be thought of as any plant growing in the wrong place at the wrong time and doing more harm than good (Parish, 1990). It is a plant that competes with crops for water, nutrients and light and reduces crop production. Paddy weeder is commonly used as a weeding tool in rice cultivation. Hunt (1983) asserted that, in the design of a rotary hoe, there must be uniform and adequate penetration of the tools. In the design of a manually operated machine, the power supplied by man working continuously should be taken into consideration. Since the paddy weeder is a manually operated weeding machine, hence the level of pressure exerted on the tool won't be same all the time, according to Verma and Sahu (2007) maximum push force that can be exerted by a human being is $245.16 \mathrm{~N}$ and maximum pull force is $215.75 \mathrm{~N}$, which is within the capability of average human and was found mechanically and ergonomically fit for the farmers of Chhattisgarh state. As a result there was an exponential growth in demand and to increase the production volume, hence proper attention must be given towards its operation, and how it is manufactured.

Kepner et al. (1978) claimed that mechanical method of weed control is the best with little or no limitation because of its effectiveness. The weeder consists mainly of cutting blades, drum, handle, and connecting rod between blade and handle. As the machining was being done manually, the various operations like punching, marking consumed ample amount of time. Moreover the setting and holding of job during machining is difficult and time consuming task. Thus the machining of the components became difficult and the production rate remained slow and further added up to their time and labour requirement, which can be reduced using some engineering solutions.

Studies revealed that there is no versatile design of weeder. However, it is a region specific technology, the design of which differs from region to region to meet the requirements of soil type, crops grown, cropping pattern and availability of local resources (Yadav, 2007). Therefore, the effort has been made to develop a weeder to meet the demand of farmers in Chhattisgarh and it was tested in the field through ergonomic point of view for its efficiency. Keeping an eye on the huge demand of the paddy weeder in the present scenario, and the workers on the other hand presently operating without jigs and fixtures, these parts are welded using visual observations using which results in the in-accuracy in dimensions, and poor workmanship and lack of interchangeability.

A jig for the aforesaid purpose has been designed and developed under the project Niche Area of Excellence, Farm Mechanization in Rainfed Agriculture, at Faculty of Agriculture Engineering workshop. It ensures the interchangeability and thus the farmers can replace and repair components without losing appropriate time during weeding operation. Mass production aims at high productivity to reduce unit cost and interchangeability to facilitate easy assembly (Ali et al., 2013). Singh 1991 found that the improvement in jigs and fixtures helped in reducing the wastage of blank material which was to the 


\section{Ankitesh Shrivastava and Ajay Verma}

extent of $43 \%$. The fabrication time in fabricating the cutting blades and roller frame was reduced by $80.43 \%$, and $43.75 \%$ respectively, by changing the design. So study was conducted to design and develop jigs and fixture for mass production of paddy weeder with reduced unit cost.

\section{MATERIALS AND METHODS}

\section{Study of Existing Process for Development of Paddy Weeder}

Paddy weeder is used as the weeding tool in the rice cultivation. Presently, the production processes were being carried out with the help of traditional jigs, the photograph of such jigs and fixtures is shown below. The unit operations used (Figure 1) in the manufacturing of these paddy weeders were marking, cutting, size marking, drilling, heat treatment, welding, assembling, priming and painting. Out of these operations, joining of the frame, cutting unit and float design requires utmost care because float is the component which is used to skid the weeder in the field in standing water condition for easy work. It gives the straight path during the weeding operation of the weeder. The float is welded to the cutting tool at the angle of 150 degree so that it can slide on soil easily (Verma and Sahu, 2007). A jig to serve this purpose has been designed and developed at Faculty of Agriculture Engineering workshop. The main parts of the jig were plate holders, side plate holders, float inclination, etc.

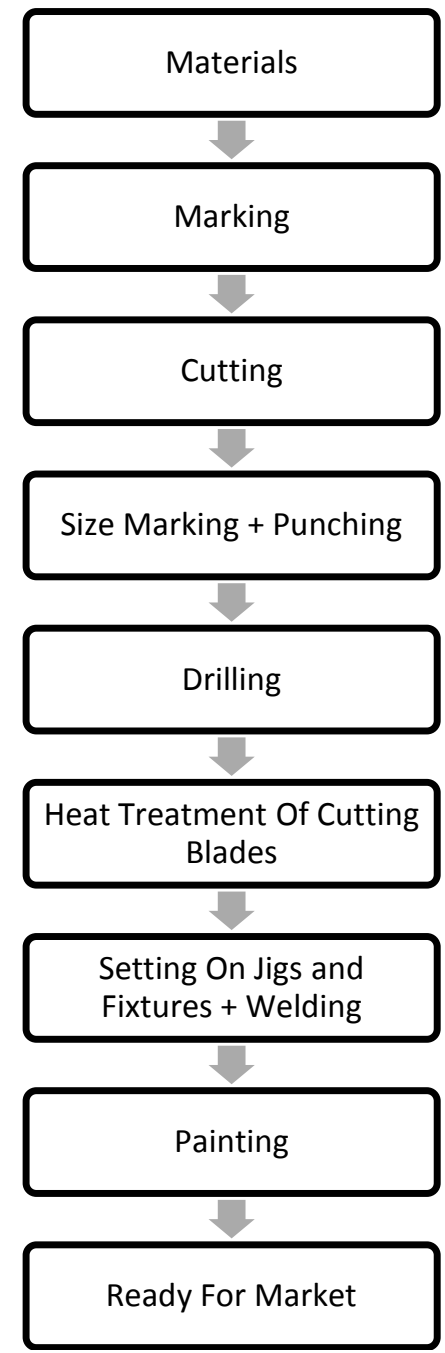

Figure 1: Production flow chart of paddy weeder
Sci. Technol. Arts Res. J., Oct-Dec 2014, 3(4): 152-157

Jigs and Fixtures Already in use for Development of Paddy Weeder

\section{Jig for Float}

The Jigs is used for the moulding of MS plate i.e. used for manufacturing float. The plates were moulded by the hand and hence took time and also generated drudgery to the worker. As a result, after working for 15 minutes and molding 15 plates, pain started in hand of the operator and after 10 minutes rest the worker again started molding. Figure 2 shows the traditional jig, used for bending the float.
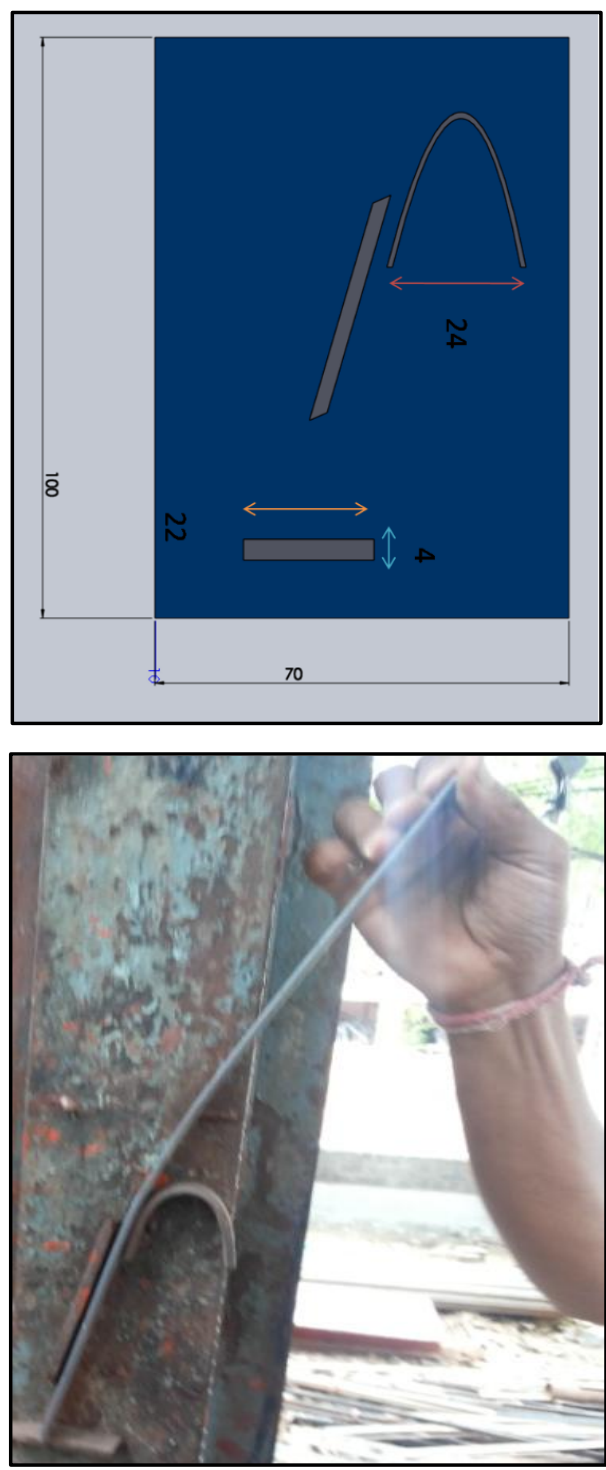

Figure 2: Traditional jig for float

\section{Welding Fixture of Paddy Weeder}

The process involves several traditional ways of executing the process. A total of 8 plates were cut with chisel and hammer. The plates were adjusted in the fixture for welding purpose. Firstly, temporary welding is done to hold plates and after that final welding was done to complete the work piece. Figure 3 shows the developed welding fixture. 

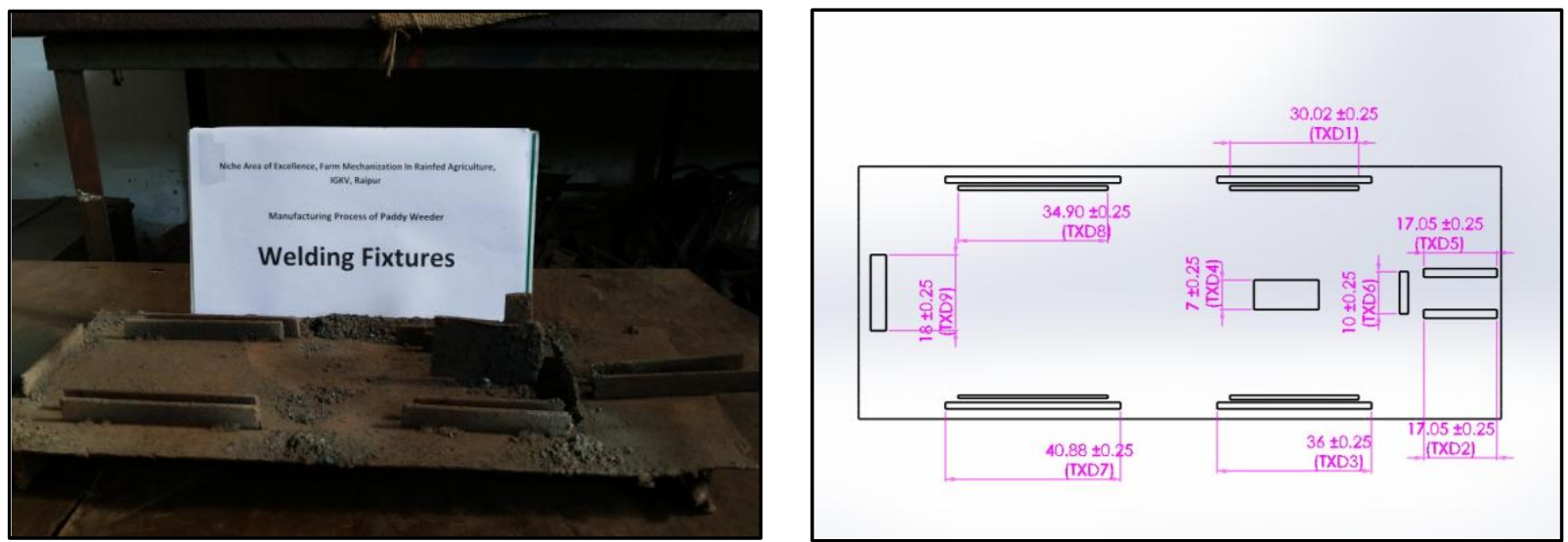

Figure 3: Jig for welding fixture

\section{RESULTS AND DISCUSSION}

Development of the Jigs, Fixtures and Dies for Large Production of Paddy Weeder

To produce paddy weeder in large quantity and with low cost, Power press attachment Jigs and Fixtures were developed. By the use of Jigs and Fixtures efforts of marking, measuring and setting of work-piece on a machine were reduced and accuracy of performance was also maintained. The work-piece and tool were relatively located at their exact positions before the operation automatically within negligible time, hence reduction in product cycle time was observed. Due to low variability in dimension, assembly operation becomes easy with low rejection due to less defective production was observed. It reduces the production cycle time and increases production capacity.

Working simultaneously by more than one tool on the same work-piece was possible. There was no need to examine the quality of output, provided that quality of employed jigs and fixtures was ensured. The hand operated jigs for molding the MS plate in right angles and moulding plate for development of float of paddy weeder is developed. The rate of welding got halved with the use of improved jigs, with the traditional jigs the welding was needed 12 times and now welding was completed in only five times, resulting in saving of time and material used, hence reducing the costs associated with production. Figure 4 shows the hand operated press and the frame developed with its implementation.

Designing of jigs and fixtures depends upon some factors, these factors were analyzed to get design inputs for jigs and fixtures viz. study of work piece and finished component size and geometry, type and capacity of the machine, its extent of automation, provision of locating devices in the machine, evaluation of variability in the performance results of the machine, required level of the accuracy in the work and quality to be produced.
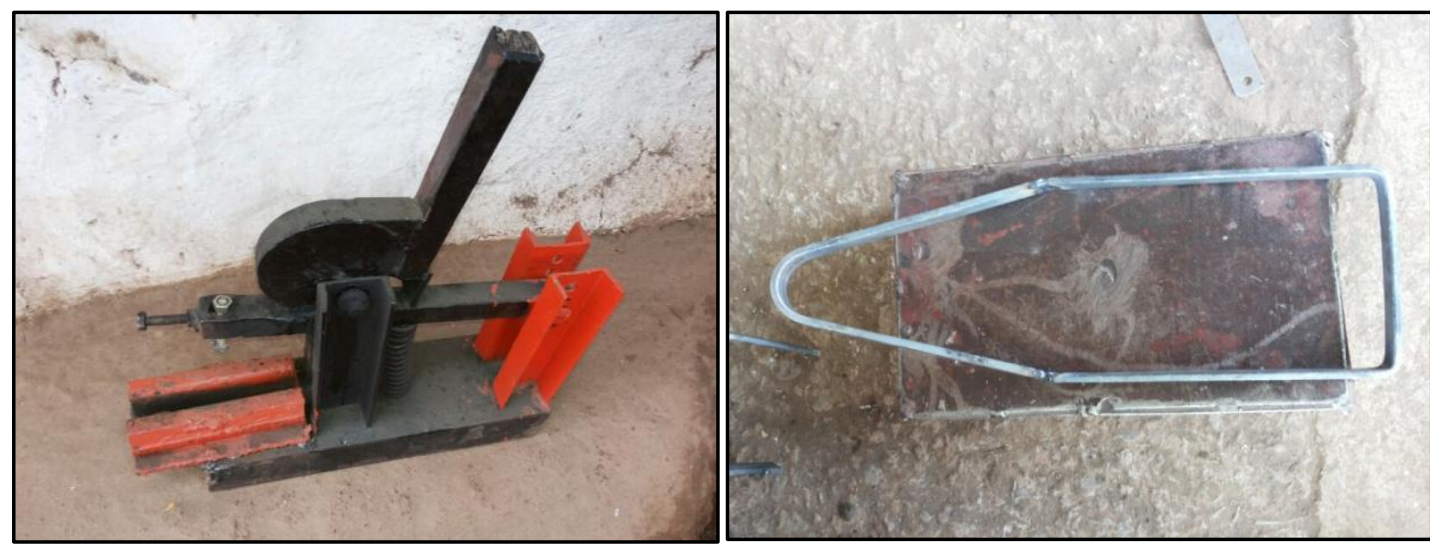

Figure 4: Improved Jigs and fixture for main frame

\section{Design and Development of improved Jigs and Fixtures}

The traditional jigs and fixtures proved helpful in increasing the production units per unit time, saving the time consumed in the process. The thorough study of the entire process, it was found that all the above mentioned parameters can further be improved with the help of improved jigs and fixtures. Hence, the designing of dies helpful in the production of paddy weeder was done with the help of designing software solid works shown in Figure 5. Once the designing was done, the jigs were developed.
One die was designed and developed for creating $90^{\circ}$ bends on the MS plates. Figure 5 shows the generated designs for the production. Hence, eliminating the need for joints made and reducing the amount of welding operation performed. For creating the float, having an semi-elliptical shape, a set of fixtures were also designed between which, plates are placed and so pressed that the shape for the float is created. Each and every operation was performed using traditional and improved jigs, for at least 2 hours and the time consumed in it was taken using a stopwatch. Table 1 shows the average time elapsed in an operation per unit, using traditional jigs. 


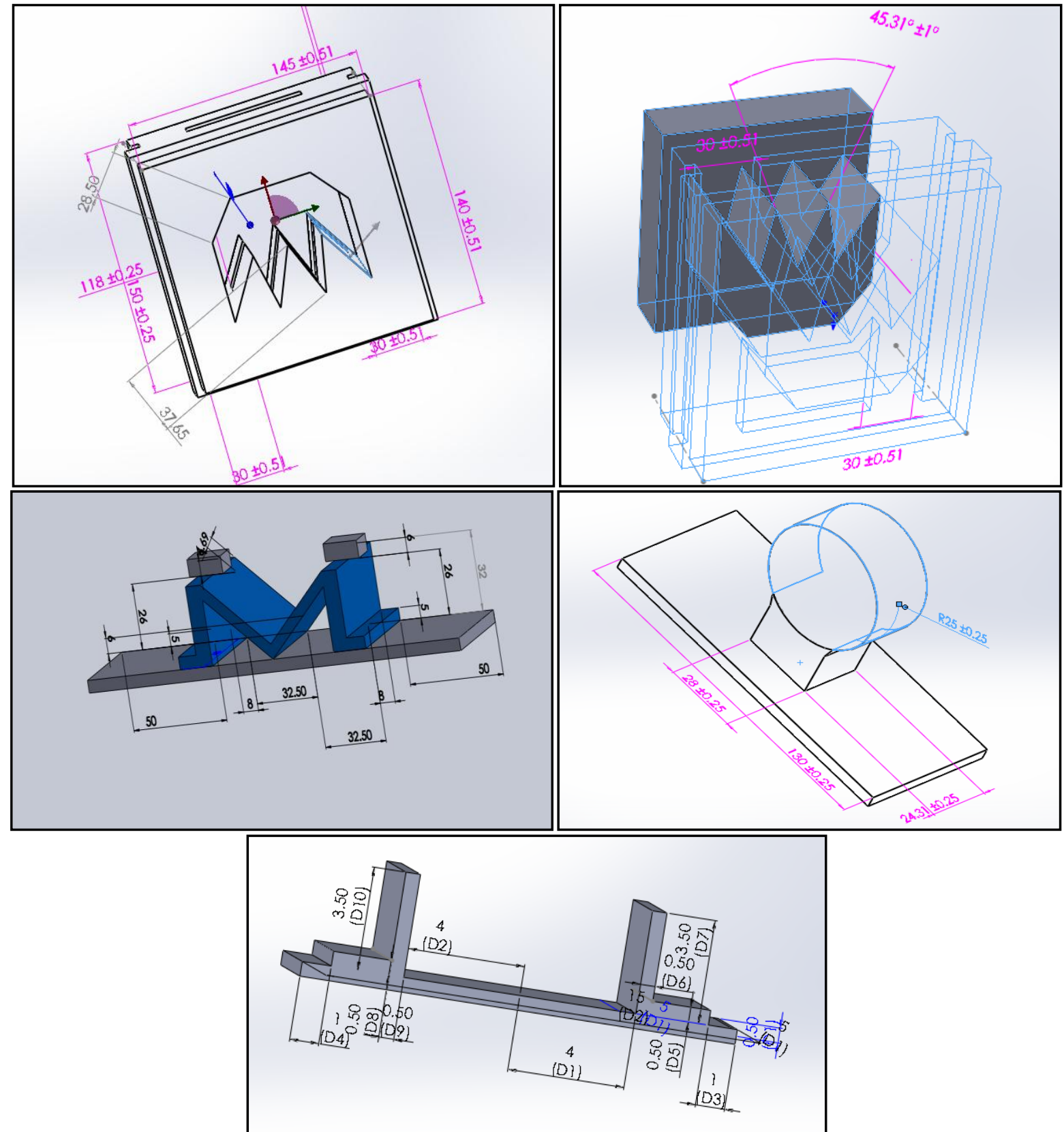

Figure 5: Drawing of developed Jigs and fixtures

Table 1: Time consumed / unit by traditional jigs (Average time / operation $=2 \mathrm{~h}$.)

\begin{tabular}{clc}
\hline No & Operations Performed & Avg. Time Consumed (in sec.) \\
\hline $\mathbf{1}$ & Marking MS plate(5mm) & 20 \\
$\mathbf{2}$ & Cutting (16 inch, 8 inch x 2, 4 inch x 3,5 inch) & 60 \\
$\mathbf{3}$ & Cutting Float & 20 \\
$\mathbf{4}$ & Marking + Cutting Float Pad & 50 \\
$\mathbf{5}$ & Bending & 60 \\
$\mathbf{6}$ & Drill Marking & 70 \\
$\mathbf{7}$ & Drilling (14 drills/ piece) & 77 \\
$\mathbf{8}$ & Teeth Cutting & 180 \\
$\mathbf{9}$ & Welding (temporary + permanent) & 210 \\
$\mathbf{1 0}$ & Heat Treatment & 60 \\
$\mathbf{1 1}$ & Pipe Cutting + Drilling & 30 \\
$\mathbf{1 2}$ & Nut and Bolt Tightening & 40 \\
\hline & Total Time Elapsed & $\mathbf{8 7 7}$ \\
\hline
\end{tabular}

The prototype of the improved jigs was placed in the production cycle and were used in the production, to deliver end product. The implementation helped to verify their applicability and also helped in thoroughly evaluating them. Figure 6 and 7 shows the time consumed in fabrication process by traditional and improved jigs. 
Ankitesh Shrivastava and Ajay Verma

Table 2 shows the average time elapsed in an operation per unit, by implementing improved jigs and
Sci. Technol. Arts Res. J., Oct-Dec 2014, 3(4): 152-157

fixtures. Figure 8 shows the comparison between both the fabrication methods.

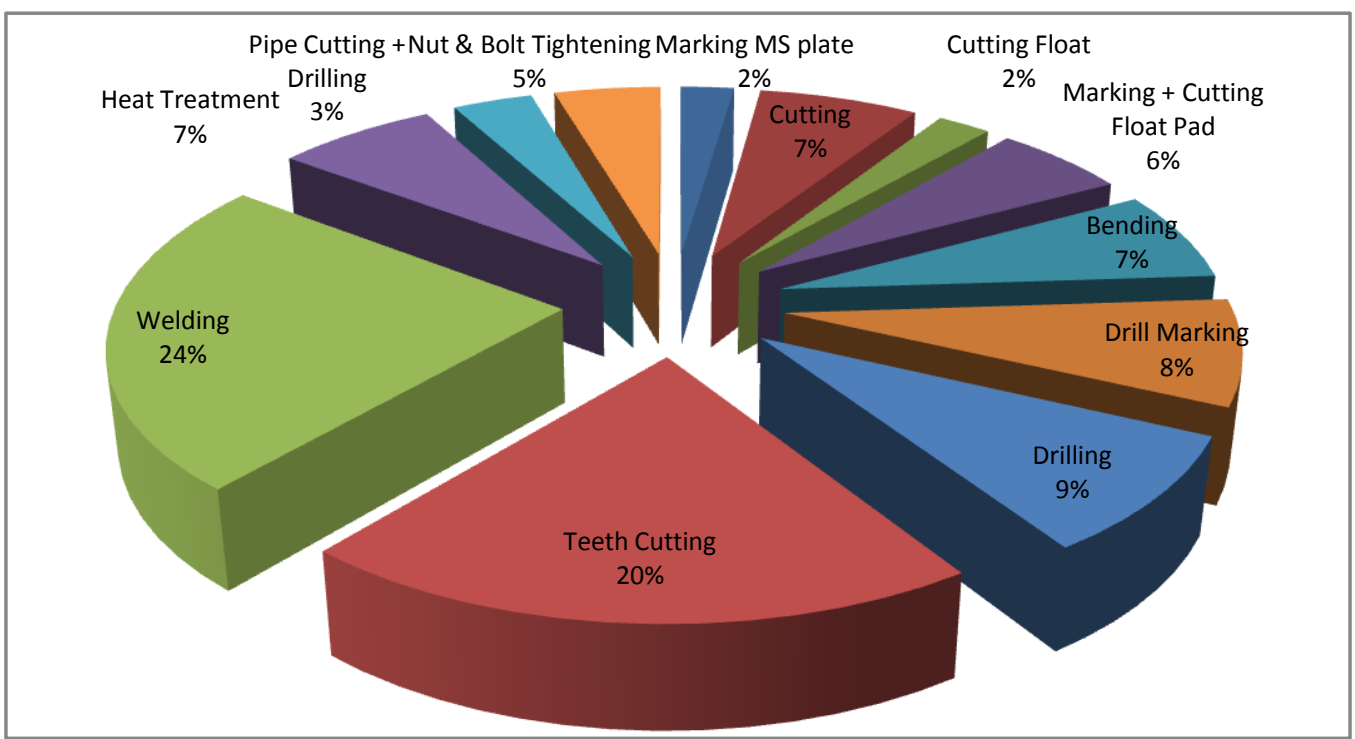

Figure 6: Time for fabrication of paddy weeder with traditional jigs and fixture

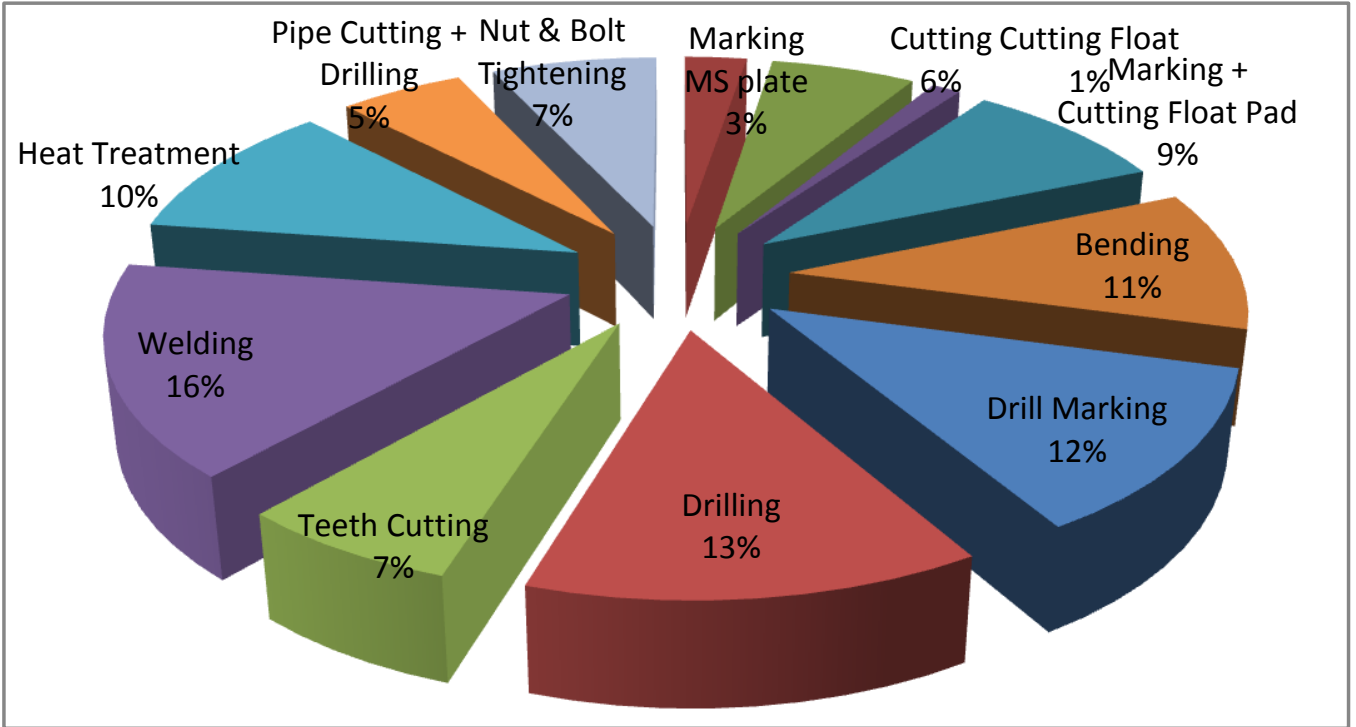

Figure 7: Time for fabrication of paddy weeder with improved jigs and fixture

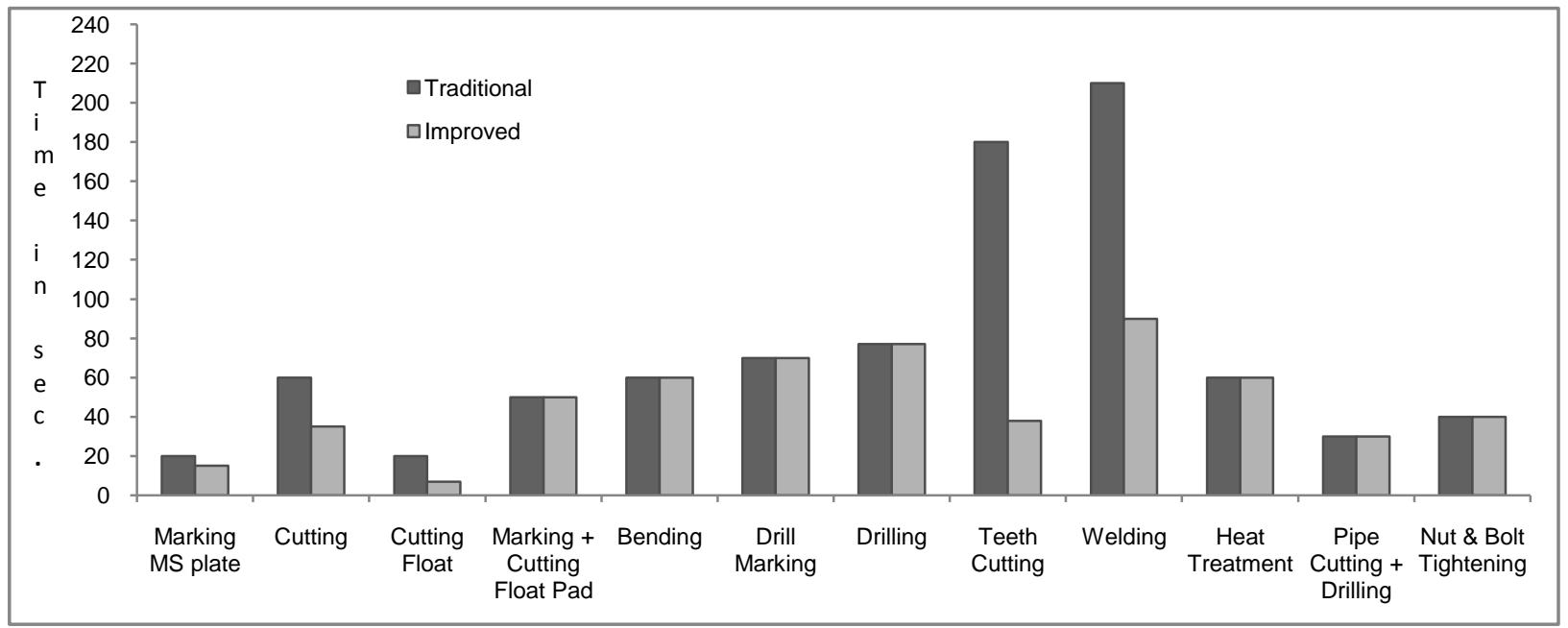

Figure 8: Comparison of manufacturing time required for development of paddy weeder with traditional and improved jigs and fixture 
Table 2: Time consumed / unit by improved jigs (Average time / operation $=2 \mathrm{~h}$ )

\begin{tabular}{clc}
\hline No & \multicolumn{1}{c}{ Operation Performed } & Time consumed (in sec.) \\
\hline $\mathbf{1}$ & Marking MS plate $(5 \mathrm{~mm})$ & 15 \\
$\mathbf{2}$ & Cutting (20 inch, 5 inch x 2, 12 inch, 16 inch) & 35 \\
$\mathbf{3}$ & Cutting Float & 07 \\
$\mathbf{4}$ & Marking + Cutting Float Pad & 50 \\
$\mathbf{5}$ & Bending & 60 \\
$\mathbf{6}$ & Die setting for punching & 12 \\
$\mathbf{7}$ & Punching & 08 \\
$\mathbf{8}$ & Teeth Cutting & 38 \\
$\mathbf{9}$ & Welding (temporary + permanent) & 90 \\
$\mathbf{1 0}$ & Heat Treatment & 60 \\
$\mathbf{1 1}$ & Pipe Cutting + Drilling & 30 \\
$\mathbf{1 2}$ & Nut and Bolt Tightening & 40 \\
\hline & Total Time Elapsed & $\mathbf{4 4 5}$ \\
\hline
\end{tabular}

\section{CONCLUSIONS}

The proper analysis of all the process parameters involved in the production of paddy weeder, some of the processes that mostly affect the timely production were found to be operation like welding and teeth cutting. Hence jigs were designed, so as to minimize the number of welding joints done, and to reduce the time consumed in teeth cutting process. The implementation of improved jigs and fixture in the production process proved to be highly successful as the average time for producing a paddy weeder with the use of these jigs was 35\% less than that of those produced with traditional jigs and fixtures. Hence, enabling the manufacturers to increase the production rate.

\section{REFERENCES}

Ali, M. and Mahalle, G. (2013). Design and analysis of weight lever drilling jig. International Journal of Pure and Applied Research in Engineering and. Technology 1(8): 177-186.
Hunt, D. (1983). Farm Power and Machinery Management. $8^{\text {th }}$ Edition. Iowa State University Press. AMES. Iowa USA.

Kepner, R.A., Bainer, R. and Barger, E.L. (1978). Principles of farm machinery, $3^{\text {rd }}$ edition, AVI publication Co., INC., Westport, Connecticut.

Parish, S. (1990). A review of non-chemical weed control techniques. Biological Agriculture and Horticulture 7: 117137.

Singh G. (1991). Development and fabrication techniques of peg-type dryland weeder. Indian Journal of Agricultural Engineering 1(2): 87-93.

Verma A., Sahu R.K. (2007). Design, development and performance evaluation studies on gender friendly rotary paddy weeder. Journal of Agricultural Issues 2(2):

Yadav, R. and Pund, S. (2007). Development and Ergonomic Evaluation of Manual Weeder. CIGR Ejournal IX: 1-9. 